\title{
Glibenclamide Mimics Metabolic Effects of Metformin in H9c2 Cells
}

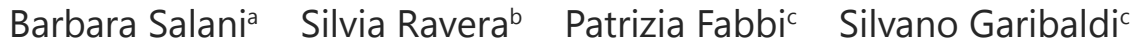 \\ Mario Passalacquad Claudio Brunellic Davide Maggia Renzo Cordera ${ }^{a}$ \\ Pietro Americ
}

aLaboratory of Metabolic Disease, Department of Internal Medicine (DiMI), University of Genova and IRCCS AOU San Martino - IST, Genova, 'Biochemistry Laboratory, Department of Pharmacy (DIFAR), University of Genova, Genova, 'Laboratory of Cardiovascular Biology, Department of Internal Medicine, University of Genova and IRCCS AOU San Martino - IST, Genova, dDepartment of Experimental Medicine, section of Biochemistry, University of'Genova, Genova, Italy

\section{Key Words}

Glibenclamide • Metformin • ATP • Cardiomyocyte • H9c2 • Metabolism

\begin{abstract}
Background: Sulfonylureas, such as glibenclamide, are antidiabetic drugs that stimulate beta-cell insulin secretion by binding to the sulfonylureas receptors (SURs) of adenosine triphosphate-sensitive potassium channels $\left(\mathrm{K}_{\text {ATP }}\right)$. Glibenclamide may be also cardiotoxic, this effect being ascribed to interference with the protective function of cardiac $\mathrm{K}_{\text {ATP }}$ channels for which glibenclamide has high affinity. Prompted by recent evidence that glibenclamide impairs energy metabolism of renal cells, we investigated whether this drug also affects the metabolism of cardiac cells. Methods: The cardiomyoblast cell line H9c2 was treated for $24 \mathrm{~h}$ with glibenclamide or metformin, a known inhibitor of the mitochondrial respiratory chain. Cell viability was evaluated by sulforodhamine B assay. ATP and AMP were measured according to the enzyme coupling method and oxygen consumption by using an amperometric electrode, while Fo-F1 ATP synthase activity assay was evaluated by chemiluminescent method. Protein expression was measured by western blot. Results: Glibenclamide deregulated energy balance of H9c2 cardiomyoblasts in a way similar to that of metformin. It inhibited mitochondrial complexes I, II and III with ensuing impairment of oxygen consumption and ATP synthase activity, ATP depletion and increased AMPK phosphorylation. Furthermore, glibenclamide disrupted mitochondrial subcellular organization. The perturbation of mitochondrial energy balance was associated with enhanced anaerobic glycolysis, with increased activity of phosphofructo kinase, pyruvate kinase and lactic dehydrogenase. Interestingly, some additive effects of glibenclamide and metformin were observed. Conclusions: Glibenclamide deeply alters cell metabolism in cardiac cells by impairing mitochondrial organization and function. This may further explain the risk of cardiovascular events associated with the use of this drug, alone or in combination with metformin.

B. Salani and S. Ravera contributed equally to this work.

(C) 2017 The Author(s)

Published by S. Karger AG, Basel
\end{abstract}

Barbara Salani

KARGER
Laboratory of Metabolic Disease, Department of Internal Medicine (DiMI),

University of Genova and IRCCS AOU San Martino - IST, Genova, (Italy)

E-Mail barbara.salani@unige.it 


\section{Introduction}

Concern exists about the cardiovascular safety of the old - yet still widely prescribed - class of antidiabetic drugs, sulfonylureas [1]. Among the sulfonylureas currently used in clinical practice, glibenclamide in particular has been associated with cardiovascular events, including acute myocardial infarction, and mortality [2, 3], consistent with data showing that glibenclamide may have cardiotoxic effects [4]. By contrast, other sulfonylureas, such as gliclazide, seem to be safer in both epidemiological studies [3] and experimental models [4]. Interestingly, further increased cardiovascular risk has been reported for glibenclamide when it is associated with metformin [2], overriding the favourable effects on cardiovascular system [5].

In pancreatic beta cells, sulfonylureas act by binding to and closing ATP-sensitive potassium channels $\left(\mathrm{K}_{\text {АтP }}\right)$, the result being an increase in intracellular $\mathrm{K}^{+}$ions, triggering of membrane depolarization, opening of voltage-dependent $\mathrm{Ca}^{2+}$ channels, intracellular $\mathrm{Ca}^{2+}$ influx and insulin secretion [6].

Cardiac toxicity of sulfonylureas has been related to the closure of specific $\mathrm{K}_{\text {ATP }}$ channels expressed in the heart [7]. Besides $\mathrm{K}_{\mathrm{ATP}}$ channels, sulfonylureas also inhibit chloride and calcium channels inducing complex ionic events $[8,9]$, which regulate cell membrane potential during oxidative stress and ischemic preconditioning. The difference in the profile of cardiovascular activity among glibenclamide and other sulfonylureas may, at least in part, depend on differences in the affinity for the $\mathrm{K}_{\mathrm{ATP}}$ channels isoforms expressed by cardiomyocytes.

$\mathrm{K}_{\text {ATP }}$ channels are expressed in both plasma and mitochondrial membranes. Recently, it has been shown that glibenclamide binds to the inner mitochondria membrane of renal tubular cells causing depletion of intracellular ATP [10]. Based on this finding, we hypothesized that glibenclamide could also alter mitochondrial function and ATP production in cardiac cells.

We compared the effects of glibenclamide and metformin (which is known to inhibit mitochondrial respiration and ATP synthesis) on cellular energy balance in the cardiomyoblast cell line H9c2. We found that glibenclamide, similar to metformin, disrupts mitochondrial reticulum organization, impairs mitochondrial oxidative phosphorylation, decreases ATP concentration, and activate phosphofructo-kinase (PFK), pyruvate kinase (PK) and lactic dehydrogenase (LDH), key enzymes of the anaerobic glycolytic pathway.

\section{Materials and Methods}

\section{Reagents}

Metformin, glibenclamide and gliclazide were provided by Sigma-Aldrich (St. Louis, MO, USA).

\section{Cell Culture}

H9c2 cells (RRID: CVCL_286) were obtained from ATCC and cultured in low glucose Dulbecco's modified Eagle's medium supplemented with 2 mM glutamine, 10\% Fetal Bovine Serum (FBS), 100 U/ml penicillin, and $100 \mathrm{mg} / \mathrm{ml}$ streptomycin sulphate at $37^{\circ} \mathrm{C}$ in $5 \% \mathrm{CO} 2$ as previously described [11].

\section{AMP/ATP Ratio Assay}

Cells were washed twice with PBS, lysed with 2.5\% PCA and sonicated in ice three times for 10 seconds. After centrifugation, supernatants containing PCA were collected and neutralized with $\mathrm{K}_{2} \mathrm{CO}_{3}$. ATP and AMP were measured according to the enzyme coupling method, following NADP/NADH reduction/oxidation at $340 \mathrm{~nm} ; 20 \mu \mathrm{g}$ of total protein were used for both assays. For ATP quantification assay, the medium contained

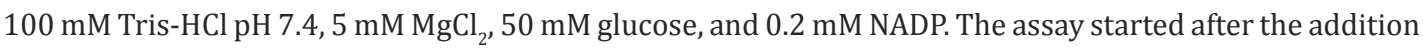
of $4 \mu \mathrm{g}$ of purified hexokinase plus glucose-6-phosphate dehydrogenase. AMP concentration was assayed using the following medium: $100 \mathrm{mM}$ Tris- $\mathrm{HCl} \mathrm{pH} \mathrm{7.4,} 5 \mathrm{mM} \mathrm{MgCl}, 10 \mathrm{mM}$ phosphoenolpyruvate, $0.15 \mathrm{mM}$ $\mathrm{NADH}$, and $0.2 \mathrm{mM}$ ATP. The assay started after the addition of $4 \mu \mathrm{g}$ of purified pyruvate kinase plus lactate dehydrogenase and $2 \mu \mathrm{g}$ of adenylate kinase $[12,13]$. 


\section{Cellular Physiology Cell Physiol Biochem 2017;43:879-890 \\ \begin{tabular}{ll|l|l} 
DOI: 10.1159/000481638 & $\begin{array}{l}\text { O } 2017 \text { The Author(s). Published by S. Karger AG, Basel } \\
\text { www.karger.com/cpb }\end{array}$ \\
and Biochemistry Published online: September 28,
\end{tabular}}

Salani et al.: Glibenclamide Depletes Cardiomyocytes of ATP

\section{Sulforodhamine B assay.}

$5 \times 10^{5} \mathrm{H} 9 \mathrm{C} 2$ cells were plated in $96 \mathrm{~mm}$ Petri dishes in regular medium. $24 \mathrm{~h}$ later, the cell medium was removed, cells were washed twice with PBS and were incubated either in regular medium or in starvation medium. $24 \mathrm{~h}$ later cells were treated or not with metformin, glibenclamide or gliclazide. 24 hours later, cell medium was removed and culture plates were fixed with cold $3 \%$ trichloroacetic acid at $4{ }^{\circ} \mathrm{C}$ for 30 minutes, washed with cold water and dried overnight. Finally, the plates were stained with $0.4 \%$ sulforodhamine B (SRB) in $1 \%$ acetic acid, washed four times with $1 \%$ acetic acid to remove unbound dye, dried overnight and solubilized with Tris base $10 \mathrm{mM}$ in $200 \mathrm{ul}$. Absorbance measurements at $560 \mathrm{~nm}$ were made using a microplate reader.

\section{Oxygen consumption measurements}

Oxygen consumption was measured at $37^{\circ} \mathrm{C}$ in a closed chamber, using an amperometric electrode (Unisense Microrespiration, Unisense A/S, Denmark). Cells were permeabilized with $0.03 \mathrm{mg} / \mathrm{ml}$ digitonin for $1 \mathrm{~min}$, centrifuged for $9 \mathrm{~min}$ at $1000 \mathrm{rpm}$ and resuspended in the appropriate buffer. The same solution was used in the oxymetric measurements. For each experiment, 200, 000 cells were used. Ten mM pyruvate plus $5 \mathrm{mM}$ malate were added to stimulate the pathway composed by complexes I, III and IV, while 20 $\mathrm{mM}$ succinate was added to stimulate the pathway formed by complexes II, III and IV. To observe the ADPstimulated respiration rates, $0.08 \mathrm{mM}$ ADP was added after pyruvate and malate and succinate addition. The respiratory rates were expressed as nmol $02 / \mathrm{min} / 106$ cells $[12,13]$.

\section{Fo-F1 ATP synthase activity assay.}

To evaluate the Fo-F1 ATP synthase activity, 200, $000 \mathrm{H} 9 \mathrm{c} 2$ cells were incubated for $10 \mathrm{~min}$ at $37^{\circ} \mathrm{C}$ in a medium containing: $10 \mathrm{mM}$ Tris- $\mathrm{HCl} \mathrm{pH} \mathrm{7.4,} 100 \mathrm{mM} \mathrm{KCl}, 5 \mathrm{mM} \mathrm{KH}_{2} \mathrm{PO}_{4}, 1 \mathrm{mM}$ EGTA, $2.5 \mathrm{mM}$ EDTA, $5 \mathrm{mM}$ $\mathrm{MgCl}_{2}, 0.6 \mathrm{mM}$ ouabain, and $25 \mathrm{mg} / \mathrm{ml}$ ampicillin. Afterward, ATP synthesis was induced by the addition of $10 \mathrm{mM}$ pyruvate plus $5 \mathrm{mM}$ malate or $20 \mathrm{mM}$ succinate, to stimulate the pathways composed by complexes I, III and IV pathway or complexes II, III and IV, respectively. To start the reaction $0.08 \mathrm{mM}$ ADP was added. The reaction was monitored for two minutes, every $30 \mathrm{sec}$, in a luminometer (GloMax® 20/20n Luminometer, Promega Italia, Milano, Italy), by the luciferin/luciferase chemiluminescent method, with ATP standard solutions between $10^{-8}$ and $10^{-5} \mathrm{M}$ (luciferin/luciferase ATP bioluminescence assay kit CLSII, Roche, Basel, Switzerland). Data were expressed as nmol ATP produced $/ \mathrm{min} / 10^{6}$ cells [14].

The oxidative phosphorylation efficiency (P/O ratio) was calculated as the ratio between the concentration of produced ATP and the amount of consumed oxygen in the presence of respiring substrates and ADP. When oxygen consumption is completed devoted to energy production, the $\mathrm{P} / \mathrm{O}$ ratio is around 2.5 and 1.5 after pyruvate + malate or succinate addition, respectively [15].

\section{Respiring Complexes assays}

The activity assay of the four redox complexes was measured on $50 \mu \mathrm{g}$ of total protein homogenate [16]. Complex I (NADH-ubiquinone oxidoreductase) was assayed following the reduction of ferricyanide at $420 \mathrm{~nm}$. Complex II (Succinic dehydrogenase) activity was measured at $600 \mathrm{~nm}$, in $2 \mathrm{mM}$ EDTA, $0.2 \mathrm{mM}$ ATP, $20 \mathrm{mM}$ succinate, $0.5 \mathrm{mM}$ cyanide, $80 \mu \mathrm{M}$ dicloroindophenol (DCIP), $50 \mu \mathrm{M}$ decylubiquinone, $40 \mu \mathrm{M}$ antimycin $\mathrm{A}, 10 \mu \mathrm{M}$ rotenone and $10 \mathrm{mM}$ phosphate buffer, $\mathrm{pH}$ 7.2. To measure complex III (Cytochrome c reductase) activity was followed the reduction of oxidized Cytochrome c at $550 \mathrm{~nm}$, in the presence of $0.7 \mathrm{mM}$ NADH, to provide the electrons, trough Complex I activity, necessary for cytochrome c reduction. Complex IV (Cytochrome c oxidase) was assayed following the oxidation of ascorbate-reduced Cytochrome $\mathrm{c}$ at $550 \mathrm{~nm}$.

\section{Western Blotting Analysis}

H9c2 cell extracts were resolved by SDS-PAGE and transferred to a nitrocellulose membrane as previously described [17]. Membranes were incubated overnight at $4{ }^{\circ} \mathrm{C}$ and probed with the following antibodies: anti pAMPK and AMPK purchased from Cell Signaling Technologies (Boston, MA), anti ND1 and anti ATP synthase (ATP5B) purchases from Sigma (St. Louis, USA) and anti actin purchased from Abcam (Cambridge, UK). Primary antibodies were detected using a goat anti-mouse or goat anti-rabbit IgG HRP conjugated, and developed with ECL substrate (Thermo Fisher Scientific, IL, USA). 


\section{Evaluation of glycolysis.}

The activities of PFK, PK and LDH were measured at room temperature on $20 \mu \mathrm{g}$ of preterm or term UCMSC total protein. Enzymatic activity was expressed as $\mathrm{mU} / \mathrm{mg}$ of total protein ( $\mathrm{nmol} / \mathrm{min} / \mathrm{mg}$ of protein). NADH molar extinction coefficient was considered $0.622 \mathrm{mM}^{-1} \mathrm{~cm}^{-1}$, at $340 \mathrm{~nm}$. The reaction mixtures used for the determination of each enzyme activity were the following [18]:

PFK (EC 2.7.1.11): $100 \mathrm{mM}$ Tris-HCl pH 7.4, $2 \mathrm{mM} \mathrm{MgCl}, 5 \mathrm{Mm} \mathrm{KCl}, 2 \mathrm{mM}$ fructose 6-phosphate, $1 \mathrm{mM}$ ATP, $0.5 \mathrm{mM}$ phosphoenolpyruvate, $0.2 \mathrm{mM} \mathrm{NADH}$, and $2 \mathrm{IU} / \mathrm{ml}$ of PK and LDH.

PK (EC 2.7.1.40): $100 \mathrm{mM}$ Tris- $\mathrm{HCl} \mathrm{pH} \mathrm{7.6,} 2.5 \mathrm{mM} \mathrm{MgCl}, 10 \mathrm{mM} \mathrm{KCl}, 0.6 \mathrm{mM}$ phosphoenolpyruvate, $0.2 \mathrm{mM} \mathrm{NADH}, 5 \mathrm{mM}$ ADP, and $1 \mathrm{IU} / \mathrm{ml}$ of LDH.

LDH (EC 1.1.1.27): $100 \mathrm{mM}$ Tris-HCl pH 7.4, $0.2 \mathrm{mM} \mathrm{NADH}$, and $5 \mathrm{mM}$ pyruvate.

\section{Immunoflurescence}

H9c2 cells were plated on glass coverslips and treated for $24 \mathrm{~h}$ with metformin $(2,5 \mathrm{mM} \mathrm{MTF})$, glibenclamide $(100 \mu \mathrm{GLB})$, or both molecules $(2,5 \mathrm{mM}$ MTF/100 $\mu \mathrm{M}$ GLB). Cells were treated using mitotracker $5 \mu \mathrm{M}$, incubated at $37^{\circ} \mathrm{C}$ for 10 minutes in the dark, washed twice and fixed with $4 \%$ PFA. Images were acquired on a Leica TCS SP confocal laser scanning microscope, equipped with 476, 488, 543 and 633 excitation lines with a 60x Plan Apo oil objective. The MitoTraker Red signal was then analyzed, after background subtraction, using ImageJ 1, 46 software (Wayne Rasband, National Institutes of Health, Bethesda, MD, USA) using a semi-manual method based on the delimitation of the cells. We measured mitochondrial morphological characteristics for each cells, as previously described [19]. Average circularity [19] was used as an indicator for mitochondrial morphological changes.

JC-1 analysis

H9c2 cells were plated in 6-well plates and treated 24h with metformin (2, $5 \mathrm{mM}$ MTF), glibenclamide $(100 \mu \mathrm{M}$ GLB), or both molecules $(2,5 \mathrm{mM}$ MTF $/ 100 \mu \mathrm{M}$ GLB$)$. At the end of treatment, cells were incubated with (1: 200) JC-1 dye (Thermo Fisher Scientific, Waltham, MA) for $15 \mathrm{~min}$ at $37^{\circ} \mathrm{C}$ in a $5 \% \mathrm{CO}_{2}$ incubator. Cells were washed and subjected to FACS analysis. The ratios of red-to-green fluorescence emissions were quantitated to further estimate the extent of mitochondrial membrane damage.

\section{Statistical Analysis}

All experiments were performed at least 3 times. Data are presented as mean \pm SEM. Comparisons were drawn by ANOVA (SPSS 16.0; SPSS, Chicago, IL) and P values $<0.05$ were considered statistically significant.

\section{Results}

To investigate whether glibenclamide could affect cell metabolism, H9c2 cardiomyoblasts were treated for $24 \mathrm{hr}$ with different doses of glibenclamide, gliclazide, or metformin. Glibenclamide caused a dose-dependent increase of the AMP/ATP ratio, indicating an impairment of the energy balance (Fig. 1 panel A). As expected, gliclazide did not modify the AMP/ATP ratio in H9c2 cells (Fig. 1 panel B). Metformin also increased the AMP/ATP ratio in this cellular model (Fig. 1 panel C). As shown in Fig. 1 panel D, glibenclamide treatment reduced cell viability in a dose-dependent manner, while gliclazide (Fig. 1 panel D) and metformin (Fig. 1 panel E) did not alter the vitality of H9C2.

Since cells respond to ATP depletion by activating AMPK, we analysed the effect of glibenclamide on AMPK phosphorylation by western blot. Again similar to metformin, and consistent with the increase in the AMP/ATP ratio, glibenclamide increased AMPK phosphorylation (Fig. 2).

The main source of ATP is oxidative phosphorylation, which occurs in mitochondria. Therefore, glibenclamide and metformin effects on mitochondrial oxygen consumption and ATP synthesis were determined. Oxygen consumption and ATP synthase activity decreased in the presence of glibenclamide in a dose dependent manner, after adding both pyruvate plus malate, a mix of substrates activating the complexes I, III and IV pathways, and succinate, which induces oxygen consumption trough the complexes II, III and IV pathways (Fig. 3 Panels 
Fig. 1. Glibenclamide increases AMP/ATP ratio and induces toxicity in $\mathrm{H} 9 \mathrm{C} 2$ cells. $\mathrm{H} 9 \mathrm{C} 2$ cells were treated for $24 \mathrm{hr}$ with different doses of $(\mathrm{A})$ glibenclamide (GLB), (B) gliclazide (GLZ) and (C) metformin (MTF); ATP and AMP concentrations were determined by enzymatic assay, and AMP/ATP ratio was then calculated. H9C2 cells were treated with increasing doses of glibenclamide and gliclazide (D) and metformin (E), $24 \mathrm{~h}$ later cells were fixed, stained and viability was detected by 96 SRB assay. Bars indicate mean \pm SE. (* $\mathrm{p}<0.05$; $* * \mathrm{p}<0.01 ; * * *<\mathrm{p} 0.001$; GraphPad Software).

A,B). By contrast, metformin treatment impaired oxygen consumption and ATP synthase activity only after the addition of pyruvate plus malate, confirming that complex I is the main metformin target [20] (Fig. 3 Panels C, D). Glibenclamide, as well as metformin, did not display any uncoupling effect. In fact, $\mathrm{P} / \mathrm{O}$ ratios ranged from 2.5 to

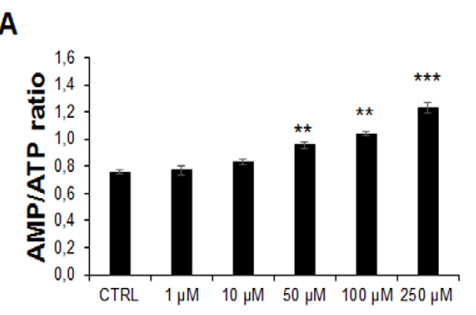

B

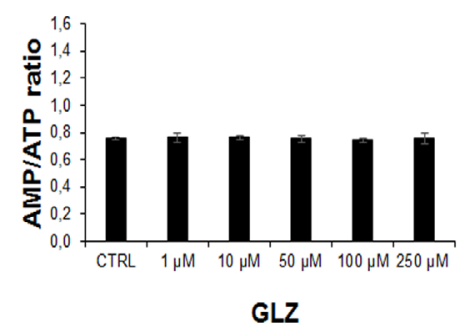

C

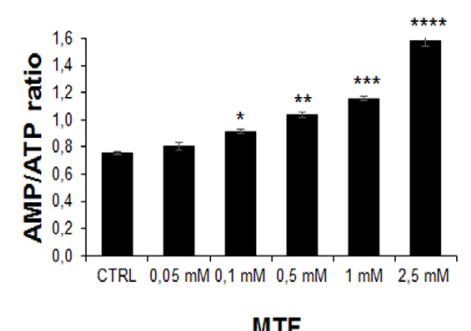

MTF
D

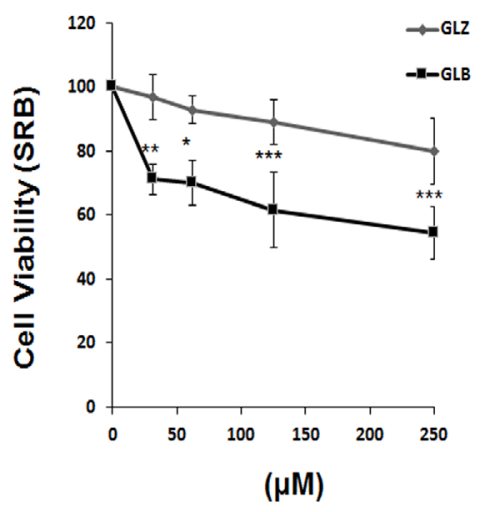

E

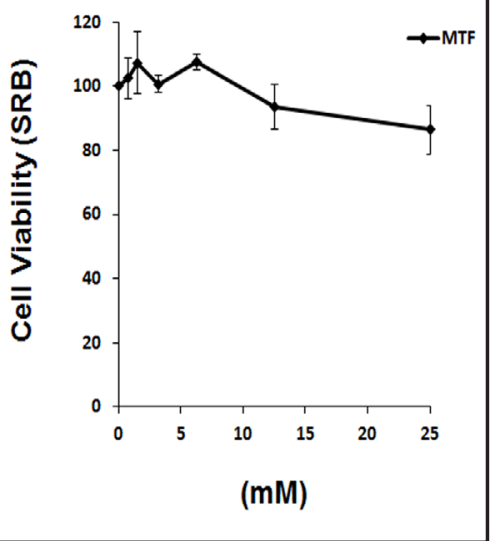

Fig. 2. Glibenclamide increases AMPK phosphorylation in H9c2 cells. H9c2 cells were treated for $24 \mathrm{hr}$ with metformin (MTF) and glibenclamide (GLB) at the indicated concentrations and levels of p-AMPK and total AMPK were examined by immunoblotting. Representative western blots and densitometric analysis of the p-AMPK signal normalized against the one of total AMPK are shown. ** $=p<0.01$ vs. control.

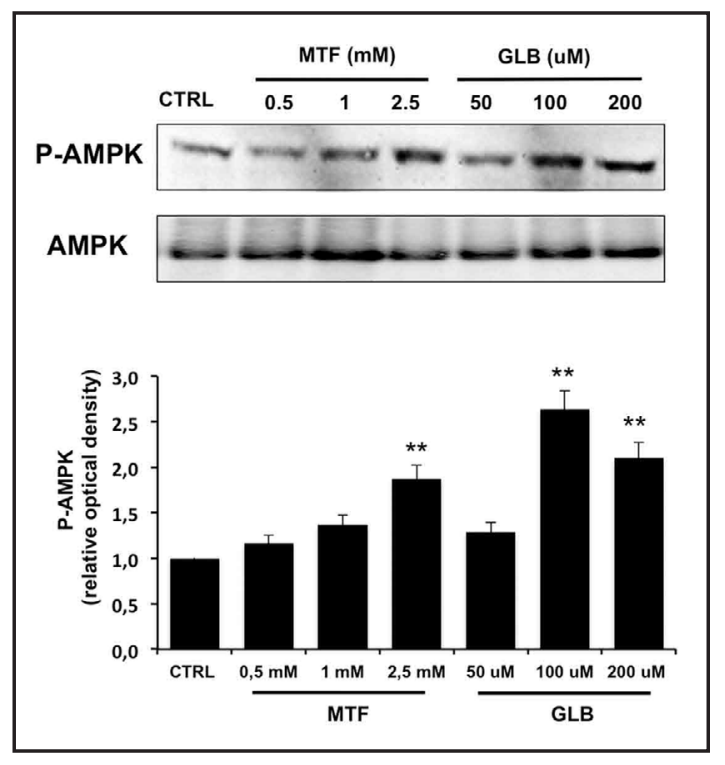

1.5 following the addition of pyruvate plus malate or succinate, respectively (Table 1).

To identify the respiratory chain target of glibenclamide, we assayed the activity of each mitochondrial respiring complex. Glibenclamide inhibited the activity of complexes I, II and III, but not of complex IV (Fig. 4 panels A, B, C, D). It is important to note that the inhibition 


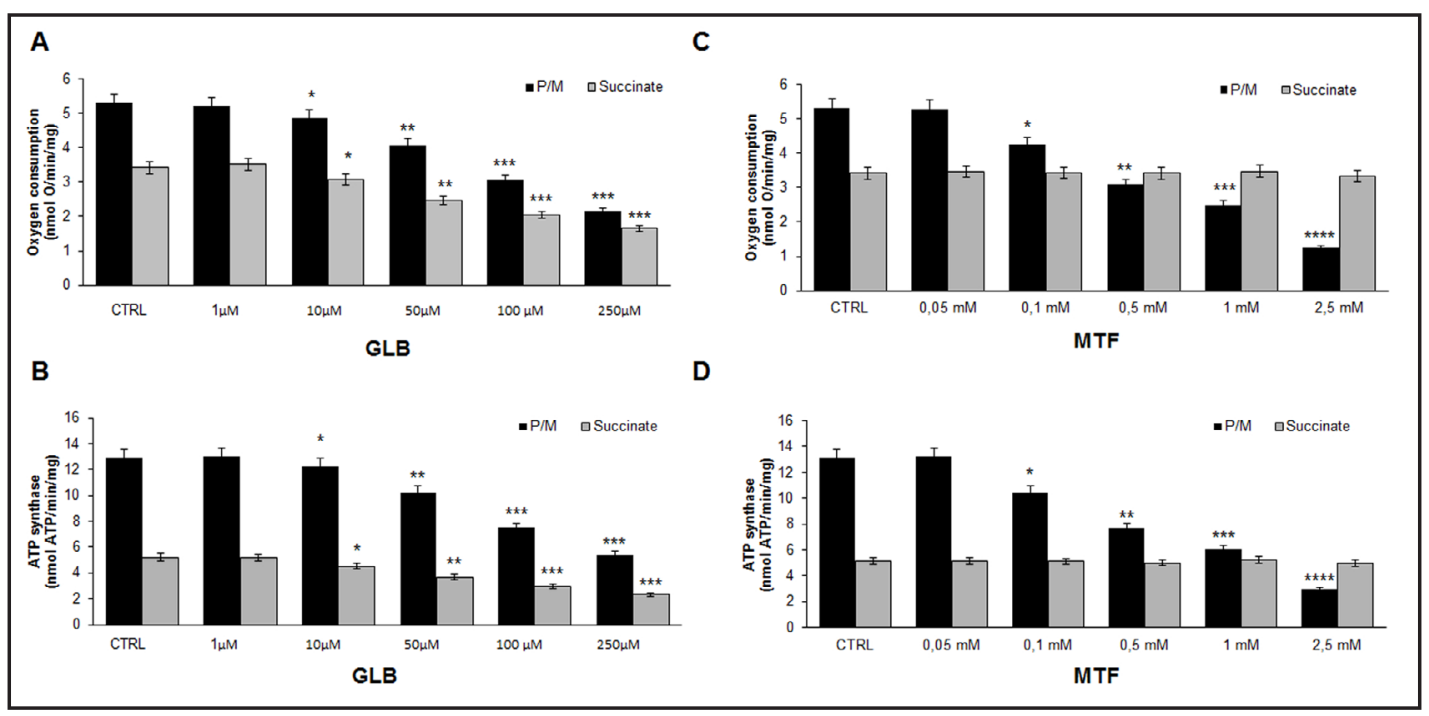

Fig. 3. Oxygen consumption and ATP synthesis in H9c2 cells treated with glibenclamide and metformin. $\mathrm{H} 9 \mathrm{c} 2$ cells were treated for $24 \mathrm{hr}$ with metformin (MTF) and glibenclamide (GLB) at the indicated concentrations. Oxygen consumption $(A, C)$ and ATP synthesis via Fo-F1 ATP synthase (B,D) were evaluated at the end of the incubation after adding pyruvate + malate (dark grey columns) or succinate (light grey columns). ${ }^{*} \mathrm{p}<0.05,{ }^{* *} \mathrm{p}<0.01$ and ${ }^{* * *} \mathrm{p}<0.005$ vs. control.

Fig. 4. Effect of glibenclamide on the mitochondrial respiring complexes. H9c2 cells were treated for $24 \mathrm{hr}$ with $250 \mu \mathrm{M}$ glibenclamide (GLB) and complex I (A), complex II (B), complex III (C) and complex IV (D) activity was measured as indicated in Materials and Methods. ${ }^{* *} \mathrm{p}<0.01$ vs. control.

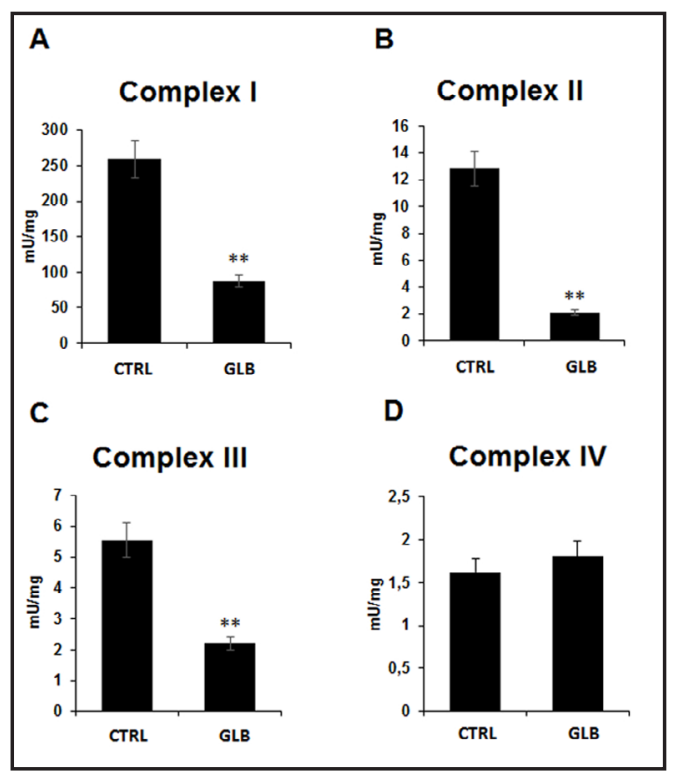

Table 1. Effect of glibenclamide or metformin on $\mathrm{P} / \mathrm{O}$ ratio. Data are the $\mathrm{P} / 0$ ratio of $\mathrm{H} 9 \mathrm{C} 2$, as the measure of the efficiency of OXPHOS metabolism, in the presence of several concentrations of glibenclamide or metformin. Data are expressed as mean \pm S.D. and represent at least three experiments

\begin{tabular}{|c|c|c|c|}
\hline & \multicolumn{2}{|c|}{ Glibenclamide (uM) } & Metformin (mM) \\
\hline & $\begin{array}{c}\mathrm{P} / \mathrm{O} \\
\text { (Pyr/Mal) }\end{array}$ & $\begin{array}{c}\mathrm{P} / \mathrm{O} \\
\text { (Succinate) }\end{array}$ & $\begin{array}{cc}\mathrm{P} / \mathrm{O} & \mathrm{P} / \mathrm{O} \\
\text { (Pyr/Mal) } & \text { (Succinate) }\end{array}$ \\
\hline CTR & $2.44 \pm 0.01$ & $1.50 \pm 0.04$ & CTR $2.45 \pm 0.031 .49 \pm 0.02$ \\
\hline 1 & $2.49 \pm 0.03$ & $1.48 \pm 0.03$ & $0.5 \quad 2.50 \pm 0.021 .47 \pm 0.02$ \\
\hline 10 & $2.53 \pm 0.01$ & $1.49 \pm 0.02$ & $0.012 .49 \pm 0.061 .51 \pm 0.04$ \\
\hline 50 & $2.57 \pm 0.08$ & $1.53 \pm 0.05$ & $0.5 \quad 2.57 \pm 0.131 .47 \pm 0.01$ \\
\hline 100 & $2.33 \pm 0.17$ & $1.46 \pm 0.02$ & $2.43 \pm 0.001 .46 \pm 0.05$ \\
\hline 250 & $2.52 \pm 0.01$ & $1.38 \pm 0.03$ & $2,5 \quad 2.25 \pm 0.181 .52 \pm 0.03$ \\
\hline
\end{tabular}

of complex III may be related with the inhibition of complex I, as this latter represents a functional component of the complex III assay (see Materials and Methods section). Thus, despite a similar final effect on oxidative phosphorylation, metformin and glibenclamide acted differently on the respiratory

chain complexes in H9c2 cells.

Then, we tested the effect of combined treatment with glibenclamide and metformin on H9c2 cells. Compared to glibenclamide alone, the addition of $2.5 \mathrm{mM}$ metformin to increasing concentrations of glibenclamide $(50-250 \mu \mathrm{M})$ significantly increased the AMP/ATP 
Fig. 5. Combined effect of glibenclamide and metformin on energetic status and oxidative phosphorylation of H9c2 cardiomyoblasts. $\mathrm{H} 9 \mathrm{c} 2$ cells were treated for $24 \mathrm{hr}$ with 2.5 $\mathrm{mM}$ metformin (MTF), increasing doses of glibenclamide (GLB), and glibenclamide/ metformin association (GLB/MTF); following treatments (A) the AMP/ATP ratio, (B) oxygen consumption, and (C) ATP synthesis were evaluated. (D) H9c2 cells were treated for $24 \mathrm{hr}$ with metformin (MTF), glibenclamide (GLB) and metformin/glibenclamide association using the indicated concentrations. $\beta$ subunit of ATP synthase and ND1 (a subunit of complex I) expression were analysed by immunoblotting. Representative western blots and densitometric analysis of the signals normalized against the one of total beta-actin are shown. ** $\mathrm{p}<0.01 * * *$ $\mathrm{p}<0.005$ vs. control.

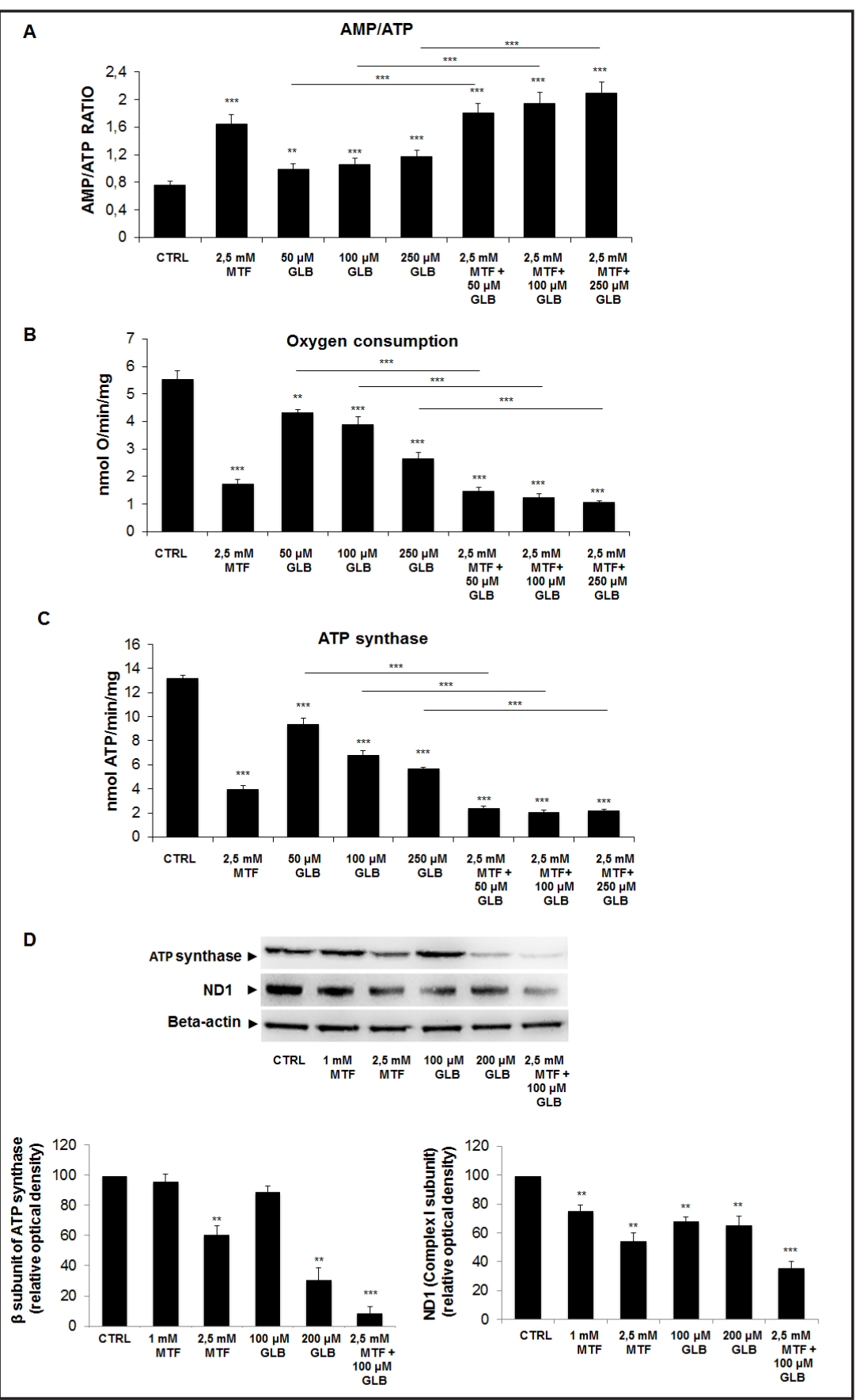

ratio, decreased oxygen consumption and ATP synthase activity (Fig. 5, Panels A, B, C). To determine the expression of respiratory chain proteins we performed western blot analysis of ND1, a subunit of Complex I and of ATP synthase ß subunit. Glibenclamide and metformin decreased the expression of both proteins, solely and in association (Fig. 5, Panel D) showing an additive effect.

Respiratory chain function may be also influenced by alterations of mitochondrial distribution in the cell. Therefore, we evaluated the organization of the mitochondrial reticulum by confocal analysis in the presence of glibenclamide, metformin or their combination after $24 \mathrm{~h}$ of treatment. After glibenclamide or metformin treatment, the mitochondrial reticulum appeared less defined than in control cells. Furthermore, mitochondria showed a more 
Fig. 6. Mitochondrial reticulum morphology after treatment with glibenclamide and metformin. (A) Representative confocal images showing the morphology and distribution of the mitochondrial reticulum in H9c2 cardiomyoblasts after 24h treatment with metformin (2,5 mM MTF), glibenclamide (100 $\mu \mathrm{M}$ GLB), or both molecules (2,5 mM MTF/100 $\mu$ M GLB). Scale bar $20 \mu \mathrm{m}$. (B) The bar diagram showed mitochondrial morphological changes analyzed by the means of circularity. (C) The bar diagram shows the ratio of JC- 1 red to green fluorescence under each treatment condition. ${ }^{*} \mathrm{p}<0,05,{ }^{* *} \mathrm{p}<0.01 \mathrm{vs}$ control. Bars indicate mean $\pm \mathrm{SE}$.

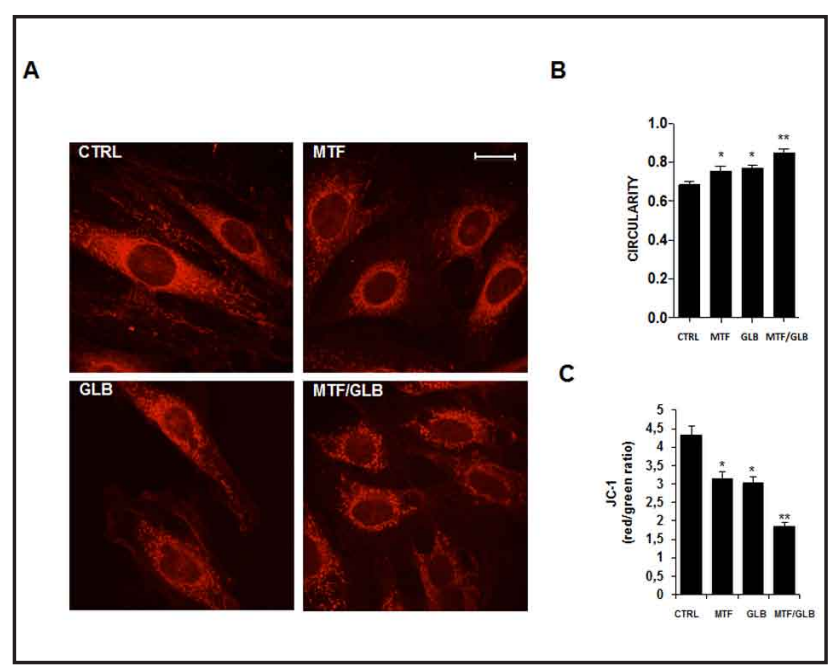

Fig. 7. Enhancement of the glycolytic flux in $\mathrm{H} 9 \mathrm{c} 2$ treated with glibenclamide and metformin. H9c2 cells were treated for $24 \mathrm{hr}$ with $2.5 \mathrm{mM}$ metformin (MTF), increasing doses of glibenclamide (GLB) (0uM-250uM) and their combination. (A) The activity of phosphofructokinase (PFK), (B) pyruvate kinase (PK) and (C) lactate dehydrogenase (LDH) was then assessed. ${ }^{*} \mathrm{p}<0.05$; $^{* *} \mathrm{p}<0.01$; $^{* * *} \mathrm{p}<0.005$ and $* * * * \quad \mathrm{p}<0.001$; vs corresponding control.

punctated distribution following combined treatment compared to the single treatments, indicating a synergistic effect of glibenclamide and metformin (Fig. 6 panel A). Moreover, to deeply characterize mitochondrial asset following treatment, mitochondrial network integrity was determined analysing circularity parameter (Fig. 6 panel B). H9C2 treated cells were labelled with mito-traker dye and subjected to confocal microscopy analysis. As shown in Fig. 6 panel C, glibenclamide, metformin and their association significantly reduced mitochondrial interconnectivity and elongation compared to the control.

$$
\text { We measured also }
$$
mitochondrial membrane potential,

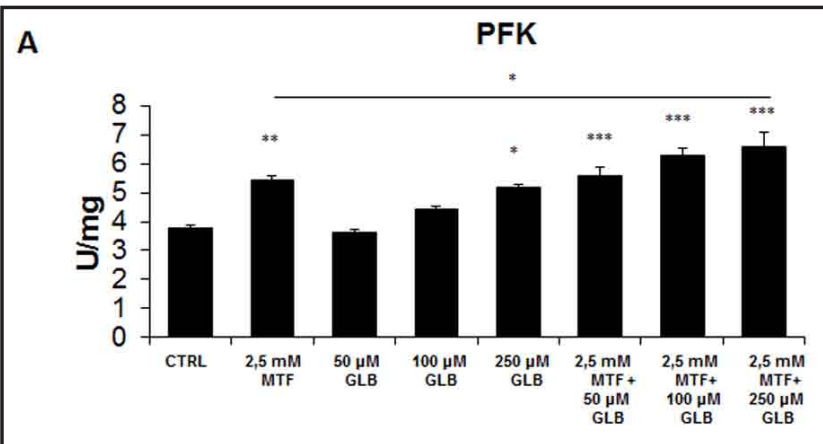

B
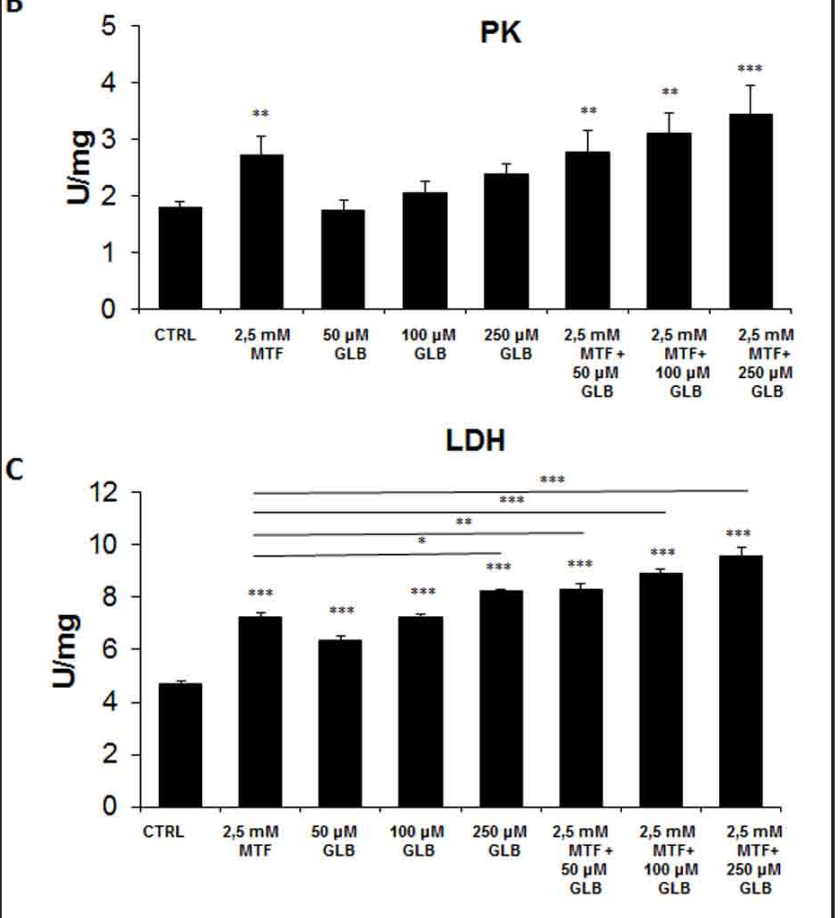
which was expressed as the absolute red/green ratio. As expected, metformin induced mitochondrial depolarization. Interestingly also glibenclamide caused a significant reduction in the red/green fluorescence 


\section{Cellular Physiology Cell Physiol Biochem 2017;43:879-890

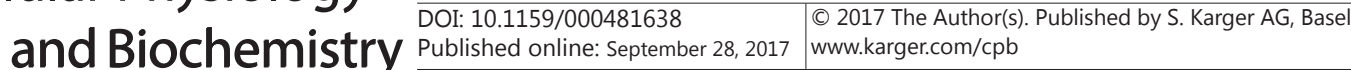

Salani et al.: Glibenclamide Depletes Cardiomyocytes of ATP

ratio indicating a drop in mitochondrial membrane potential (Fig. 6 panel C). The association of the molecules elicited a decrease in membrane potential stronger than the one triggered by either drug alone.

Finally, we examined glycolysis in H9c2 cells by measuring the activity of the PKF, PK and LDH, three key enzymes of the anaerobic glycolysis flux. As presented in Fig. 7, the activity of PKF, PK and LDH increased in the presence of metformin as well as of glibenclamide. Interestingly, we observed a further increment with the combination of the two molecules.

\section{Discussion}

This study shows that glibenclamide affects energy metabolism of H9c2 cardiomyoblasts, an established cell model for the evaluation of drug cardiotoxicity [11, 21]. Treatment of H9c2 cells with glibenclamide leads to a profound depletion of ATP, secondary to altered mitochondrial organization and oxidative phosphorylation. Overall, this metabolic perturbation is similar to the one induced by metformin, a well-known inhibitor of complex I of the respiratory chain [22].

H9c2 cardiomyoblasts express the SUR2A/Kir6.1 and SUR2A/Kir6.2 $\mathrm{K}_{\text {ATP }}$ channels isoforms [5]. To understand whether metabolic impairment by glibenclamide was $\mathrm{K}_{\text {ATP }}$ channels dependent, we also exposed the cells to equimolar concentrations of gliclazide, a second-generation sulfonylurea like glibenclamide, but with no affinity for the $\mathrm{K}_{\text {ATP }}$ channels subtypes of H9c2 cells [7]. ATP levels were not modified by gliclazide, providing indirect evidence that metabolic toxicity of glibenclamide occurs via binding to $\mathrm{K}_{\text {ATP }}$ channels. Metformin and glibenclamide are very different molecules with different mechanism of action. Similarly to metformin [23, 24] glibenclamide increases AMPK phosphorylation and mitochondrial dysfunction.

It has already been demonstrated that mitochondria express SUR and that glibenclamide can inhibit potassium fluxes in mitochondria of renal cells [10]. The functional characterization of a sulfonylurea receptor SUR2 splice variant, in fact, has been reported also in cardiac mitochondria [25]. H9c2 cells express SUR2A/Kir6.1 and SUR2A/Kir6.2 [5], which are bound by glibenclamide but not gliclazide [7]. This result suggests that binding to SUR2A/ Kir6.1 and SUR2A/Kir6.2 is necessary for glibenclamide-mediated ATP depletion. It remains to be determined whether inhibition of the respiratory chain by glibenclamide is directly mediated by mitochondrial $\mathrm{K}_{\text {ATP }}$ channels or whether it is the consequence of intracellular events triggered by glibenclamide after binding to cytoplasmic and/or mitochondrial $\mathrm{K}_{\text {ATP }}$ channels [26]. Mitochondria reticulum integrity is necessary to maintain cell energy balance. We found that glibenclamide disrupts mitochondria reticulum integrity similarly to inhibitors of the respiratory chain such as piericidin and myxothiazol that cause fission of mitochondria [27]. Our data show that metformin also causes mitochondria to switch from an elongated, tubular shape to a punctate one. This perturbation in mitochondrial organization could be related to the energy balance dysfunction observed with both molecules.

Metformin directly inhibits complex I $[28,29]$ while glibenclamide inhibits complexes I-II-III. These findings suggest that glibenclamide and metformin combined treatment could potentiate each other respiratory chain destabilization. Here metformin but also glibenclamide reduced the expression of ND1 and ATP synthase $\beta$ subunit. This result could be related to the impairment of oxidative phosphorylation. Since ND1 and ATP synthase $\beta$ subunit are codified by two different subcellular compartments, respectively mitochondria and nucleus, a transcriptional mechanism is unlikely. An alternative explanation could be that glibenclamide binds to the mitochondria inner membrane.

Metformin action on mitochondria is well established. Metformin decreases the functionality of complex I [20]. The inhibition of complex I could be a generic effect resulting from molecular changes occurring in the inner mitochondrial membrane following the binding of metformin to phospholipids $[22,30]$. Interestingly it has been shown that glibenclamide can bind to the inner membrane of mitochondria [10]. This mechanism could 
interfere with the conformations of important mitochondrial proteins, including respiratory chain complexes.

Clinical trials and registries have consistently shown that metformin does not increase cardiovascular morbidity and mortality of diabetic patients; in fact, a favourable effect of metformin on diabetes-related cardiovascular risk has been reported [5]. Consistently, most experimental studies have demonstrated that metformin prevents ischemic cardiac damage, this protection being ascribed to various pathways, not necessarily downstream of the reduction in complex I activity, such as activation of AMPK and phosphoinositide 3-kinase/ AKT, enhanced intramyocardial availability of adenosine, blunting of oxidative stress, and inhibition of mitochondrial permeability transition pore opening [24, 31]. By contrast, therapy with glibenclamide has been associated with negative cardiovascular outcomes in epidemiological analysis [2,3] and glibenclamide has been shown to worsen ischemic injury of cardiomyocytes in cell and animal models [31]. This toxicity has been primarily related to the closure of $\mathrm{K}_{\mathrm{ATP}}$ channels [7]. Here we describe that glibenclamide also elicits a drop in ATP concentrations in cardiac cells like metformin. Nonetheless, glibenclamide, but not metformin decreased H9c2 cell viability in our experiments. Further work is needed to better understand mechanisms of this difference and to dissect the actions of glibenclamide and metformin on $\mathrm{H} 9 \mathrm{c} 2$ cells. The combined effect of glibenclamide and metformin will deserve particular attention, as clinical investigations pointed to an increased cardiovascular risk when diabetic patients are given both drugs [2].

In our model, gliclazide did not modify the AMP/ATP ratio. Even though this finding cannot be extrapolated to cell types other than the H9c2 line, it is in good agreement with the literature suggesting that gliclazide is safer than glibenclamide as far as cardiovascular outcomes are concerned and, thereby, represents a valid therapeutic option for type 2 diabetes [32].

\section{Conclusion}

The experiments presented here add new data on the effects of glibenclamide on cardiac cells, showing that this drug interferes with mitochondrial organization and inhibits oxidative phosphorylation. This may further explain the risk of cardiovascular events associated with glibenclamide use. Furthermore, changes in energy metabolism should be taken into account by future investigations addressing the effects of glibenclamide on cardiac cells or the whole heart.

\section{Acknowledgements}

This work was supported by a grant from Ministero dell'Istruzione, dell'Università e della Ricerca Scientifica (MIUR) (Progetto di Rilevanza Nazionale PRIN).

\section{Disclosure Statement}

The authors have nothing to disclose.

\section{References}

\footnotetext{
1 Abdelmoneim AS, Eurich DT, Light PE, Senior PA, Seubert JM, Makowsky MJ, Simpson SH: Cardiovascular safety of sulphonylureas: Over 40years of continuous controversy without an answer. Diabetes Obes Metab 2015;17:523.
} 


\section{Cellular Physiology Cell Physiol Biochem 2017;43:879-890

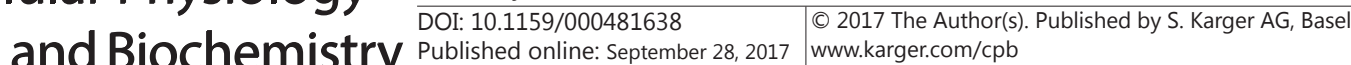

2 Evans J, Ogston S, Emslie-Smith A, Morris A, Evans JM, Ogston SA, Emslie-Smith A, Morris AD: Risk of mortality and adverse cardiovascular outcomes in type 2 diabetes: a comparison of patients treated with sulfonylureas and metformin. Diabetologia 2006;49:930-936.

-3 Schramm TK, Gislason GH, Vaag A, Rasmussen JN, Folke F, Hansen ML, Fosbøl EL, Køber L, Norgaard ML, Madsen M, Hansen PR, Torp-Pedersen C: Mortality and cardiovascular risk associated with different insulin secretagogues compared with metformin in type 2 diabetes, with or without a previous myocardial infarction: a nationwide study. Eur Hear J 2011;32:1900-1908.

4 Gribble FM, Ashcroft FM: Sulfonylurea sensitivity of adenosine triphosphate-sensitive potassium channels fromcells and extrapancreatic tissues. Metabolism 2000;49:3-6.

-5 Holman RR, Paul SK, Bethel MA, Matthews DR, Neil HAW: 10-Year Follow-up of Intensive Glucose Control in Type 2 Diabetes. N Engl J Med 2008;359:1577-1589.

-6 Shibasaki T, Takahashi T, Takahashi H, Seino S: Cooperation between cAMP signalling and sulfonylurea in insulin secretion. Diabetes, Obes Metab 2014;16:118-125.

7 Tinker A, Aziz Q, Thomas A: The role of ATP-sensitive potassium channels in cellular function and protection in the cardiovascular system. Br J Pharmacol 2014;171:12-23.

8 Kominkova V, Ondrias K, Tomaskova Z: Inhibitory effect of glybenclamide on mitochondrial chloride channels from rat heart. Biochem Biophys Res Commun 2013;434:836-840.

$\checkmark 9$ Lee S-Y, Lee CO: Inhibition of Na+-K+ pump and L-type Ca2+ channel by glibenclamide in Guinea pig ventricular myocytes. J Pharmacol Exp Ther 2005;312:61-68.

10 Engbersen R, Masereeuw R, van Gestel M a, van der Logt EMJ, Smits P, Russel FGM: Glibenclamide depletes ATP in renal proximal tubular cells by interfering with mitochondrial metabolism. Br J Pharmacol 2005;145:1069-1075.

11 Altieri P, Barisione C, Lazzarini E, Garuti A, Bezante GP, Canepa M, Spallarossa P, Tocchetti CG, Bollini S, Brunelli C, Ameri P: Testosterone Antagonizes Doxorubicin-Induced Senescence of Cardiomyocytes. J Am Heart Assoc 2016;5. DOI: 10.1161/JAHA.115.002383

12 Ravera S, Vaccaro D, Cuccarolo P, Columbaro M, Capanni C, Bartolucci M, Panfoli I, Morelli A, Dufour C, Cappelli E, Degan P: Mitochondrial respiratory chain Complex I defects in Fanconi anemia complementation group A. Biochimie 2013;95:1828-1837.

13 Columbaro M, Ravera S, Capanni C, Panfoli I, Cuccarolo P, Stroppiana G, Degan P, Cappelli E: Treatment of FANCA Cells with Resveratrol and N-Acetylcysteine: A Comparative Study. PLoS One 2014;9:e104857.

14 Ravera S, Aluigi MG, Calzia D, Ramoino P, Morelli A, Panfoli I: Evidence for ectopic aerobic ATP production on C6 glioma cell plasma membrane. Cell Mol Neurobiol 2011;31:313-321.

15 Hinkle PC: P/O ratios of mitochondrial oxidative phosphorylation. Biochim Biophys Acta 2005;1706:1-11.

- 16 Bianchi G, Martella R, Ravera S, Marini C, Capitanio S, Orengo A, Emionite L, Lavarello C, Amaro A, Petretto A, Pfeffer U, Sambuceti G, Pistoia V, Raffaghello L, Longo VD: Fasting induces anti-Warburg effect that increases respiration but reduces ATP-synthesis to promote apoptosis in colon cancer models. Oncotarget 2015;6:11806-11819.

17 Salani B, Maffioli S, Hamoudane M, Parodi A, Ravera S, Passalacqua M, Alama A, Nhiri M, Cordera R, Maggi D: Caveolin-1 is essential for metformin inhibitory effect on IGF1 action in non-small-cell lung cancer cells. FASEB J 2012;26:788-798.

18 Ravera S, Bartolucci M, Calzia D, Aluigi MG, Ramoino P, Morelli A, Panfoli I: Tricarboxylic acid cyclesustained oxidative phosphorylation in isolated myelin vesicles. Biochimie 2013;95:1991-1998.

19 Charli A, Jin H, Anantharam V, Kanthasamy A, Kanthasamy AG: Alterations in mitochondrial dynamics induced by tebufenpyrad and pyridaben in a dopaminergic neuronal cell culture model. Neurotoxicology 2016;53:302-313.

20 Owen MR, Doran E, Halestrap AP: Evidence that metformin exerts its anti-diabetic effects through inhibition of complex 1 of the mitochondrial respiratory chain. Biochem J 2000;348 Pt 3:607-614.

21 Lazzarini E, Balbi C, Altieri P, Pfeffer U, Gambini E, Canepa M, Varesio L, Bosco MC, Coviello D, Pompilio G, Brunelli C, Cancedda R, Ameri P, Bollini S: The human amniotic fluid stem cell secretome effectively counteracts doxorubicin-induced cardiotoxicity. Sci Rep 2016;6:29994.

-22 Salani B, Del Rio A, Marini C, Sambuceti G, Cordera R, Maggi D: Metformin, cancer and glucose metabolism. Endocr Relat Cancer 2014;21:R461-R471. 


\section{Cellular Physiology Cell Physiol Biochem 2017;43:879-890 and Biochemistry DOI: 10.1159/000481638 \begin{tabular}{l|l} 
O 2017 The Author(s). Published by S. Karger AG, Basel \\
www.karger.com/cpb
\end{tabular}

23 Huang M-Q, Zhou C-J, Zhang Y-P, Zhang X-Q, Xu W, Lin J, Wang P-J: Salvianolic Acid B Ameliorates Hyperglycemia and Dyslipidemia in db/db Mice through the AMPK Pathway. Cell Physiol Biochem 2016;40:933-943.

24 Hu M, Ye P, Liao H, Chen M, Yang F: Metformin Protects H9C2 Cardiomyocytes from High-Glucose and Hypoxia/Reoxygenation Injury via Inhibition of Reactive Oxygen Species Generation and Inflammatory Responses: Role of AMPK and JNK. J Diabetes Res 2016;2016:2961954.

25 Ye B, Kroboth SL, Pu JL, Sims JJ, Aggarwal NT, McNally EM, Makielski JC, Shi NQ: Molecular identification and functional characterization of a mitochondrial sulfonylurea receptor 2 splice variant generated by intraexonic splicing. Circ Res 2009;105:1083-1093.

-26 Bao L, Hadjiolova K, Coetzee W a, Rindler MJ: Endosomal KATP channels as a reservoir after myocardial ischemia: a role for SUR2 subunits. Am J Physiol Heart Circ Physiol 2011;300:H262-H270.

-27 Pletjushkina OY, Lyamzaev KG, Popova EN, Nepryakhina OK, Ivanova OY, Domnina LV, Chernyak BV, Skulachev VP: Effect of oxidative stress on dynamics of mitochondrial reticulum. Biochimi. Biochim Biophys Acta - Bioenerg 2006;1757:518-524.

-28 Wheaton WW, Weinberg SE, Hamanaka RB, Soberanes S, Sullivan LB, Anso E, Glasauer A, Dufour E, Mutlu GM, Budigner GS, Chandel NS: Metformin inhibits mitochondrial complex I of cancer cells to reduce tumorigenesis. Elife 2014;3:e02242.

29 Marini C, Bianchi G, Buschiazzo A, Ravera S, Martella R, Bottoni G, Petretto A, Emionite L, Monteverde E, Capitanio S, Inglese E, Fabbi M, Bongioanni F, Garaboldi L, Bruzzi P, Orengo AM, Raffaghello L, Sambuceti G: Divergent targets of glycolysis and oxidative phosphorylation result in additive effects of metformin and starvation in colon and breast cancer. Sci Rep 2016;6:19569.

-30 Drahota Z, Palenickova E, Endlicher R, Milerova M, Brejchova J, Vosahlikova M, Svoboda P, Kazdova L, Kalous M, Cervinkova Z, Cahova M: Biguanides inhibit complex I, II and IV of rat liver mitochondria and modify their functional properties. Physiol Res 2014;63:1-11.

-31 Ye Y, Perez-Polo JR, Aguilar D, Birnbaum Y: The potential effects of anti-diabetic medications on myocardial ischemia-reperfusion injury. Basic Res Cardiol 2011;106:925-952.

32 Mazzucchelli C, Bordone C, Maggi D, Cordera R: Comment on Inzucchi et al. Management of Hyperglycemia in Type 2 Diabetes, 2015: A Patient-Centered Approach. Update to a Position Statement of the American Diabetes Association and the European Association for the Study of Diabetes. Diabetes Care 2015;38. Diabetes Care 2015;38:e125-126. 